\title{
Effect of Mechanical Treatment Temperature on Electrical Properties and Crystallite Size of PVDF Film
}

\author{
Ambran Hartono ${ }^{1 *}$, Suparno Satira $^{2}$, Mitra Djamal $^{2}$, Ramli Ramli $^{3}$, Herman Bahar $^{2}$, Edi Sanjaya $^{1}$ \\ ${ }^{1}$ Department of Physics, Faculty of Science and Technology, Islamic State University Syarif Hidayatullah, \\ Jakarta, Indonesia \\ ${ }^{2}$ Theoretical High Energy Physics and Instrumentation Research Group, Faculty of Mathematics and Natural Sciences, Institut \\ Teknologi Bandung, Bandung, Indonesia \\ ${ }^{3}$ Department of Physics, Faculty of Mathematics and Natural Sciences, Universitas Negeri Padang, \\ Padang, Indonesia \\ Email: *ambranhartono@yahoo.com
}

Received January 11, 2013; revised February 16, 2013; accepted February 25, 2013

\begin{abstract}
Fabrication of PVDF films has been making using Hot Roll Press. Preparation of samples carried out for nine different temperatures. This condition is carried out to see the effect of temperature fabrication on electrical properties and crystallite size of PVDF films. The electrical properties like as surface resistivity are discussion focus in this paper. Surface resistivity properties of PVDF can be improved by mechanical treatment on the varying film thickness and the temperature. To obtain the diffraction pattern of sample characterization is performed using X-Ray Diffraction. Crystallite size of PVDF films calculate from broadening pattern of X-Ray Diffraction. Furthermore, from the diffraction pattern calculated $\beta$ fraction and crystallite size, for calculation to determine the crystallite size of the sample by using the Scherrer equation. Has been obtained an increase piezoelectric properties of PVDF films that characterized by increasing $\beta$ fraction. Have been obtained $\beta$ fraction increased from $25.4 \%$ up to $44 \%$ for temperatures of $130^{\circ} \mathrm{C}$ up to $170^{\circ} \mathrm{C}$, respectively. Resistivity value has been obtained at temperature $130^{\circ} \mathrm{C}$ up to $170^{\circ} \mathrm{C}$, decreased from $1.23 \times 10^{4} \Omega \mathrm{m}$ up to $0.21 \times 10^{4} \Omega \mathrm{m}$ respectively. From the experimental results and the calculation of crystallite sizes obtained for the samples with temperature $130^{\circ} \mathrm{C}$ up to $170^{\circ} \mathrm{C}$ respectively are increased from $7.2 \mathrm{~nm}$ up to $20.54 \mathrm{~nm}$. These results indicate that mechanical treatment caused increase $\beta$ fraction and decrease surface resistivity. Increasing temperatures will also increase the size of the crystallite of the sample. This happens because with the increasing temperature causes the higher the degree of crystallization of PVDF film sample is formed, so that the crystallite size also increases.
\end{abstract}

Keywords: Crystallite Size; PVDF; Roll Hot Press; Scherrer Equation; Surface Resistivity; Temperature Different; XRD

\section{Introduction}

Recently, the development of manufacturing technology and utilization of polymer films are increasing rapidly, especially polyvinylidene fluoride (PVDF) polymer. PVDF is a material typically used for applications requiring high purity when compared to other fluoropolymer. PVDF easier to melt due to have a low melting point [1]. PVDF can be synthesized from the gaseous VDF monomers via free radical polymerization process are shown in Figure 1.

PVDF polymer has three solid molecule structures that are $\beta$-phase, $\alpha$-phase and $\gamma$-phase [2]. Chain agglomerations of $\alpha$-phase in PVDF are shown in Figure 2.

$\alpha$-phase of PVDF polymer have TGTG type conformation structure [2]. PVDF polymer with $\beta$-phase mole-

${ }^{*}$ Corresponding author. cule structure is shown in Figure 3.

Recently, PVDF with $\beta$-phase structure are widely developed due to molecules with this structure provides the greatest piezoelectric effect compared with other phase.

$\beta$-phase have planar zig-zag formation which all trans (TTTT) [3] with deflection small because of fluor atoms bonded by nearest monomer.

The electrical properties like as piezoelectric are related to the $\beta$ fraction PVDF polymer and surface resis-

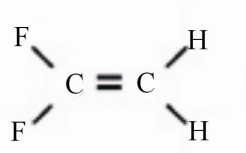

Vinylidene fluoride

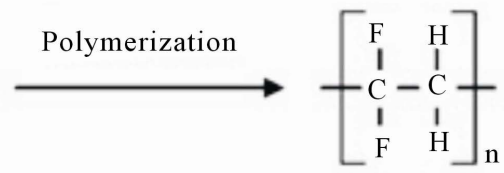

PVDF
Figure 1. Polymerization process. 

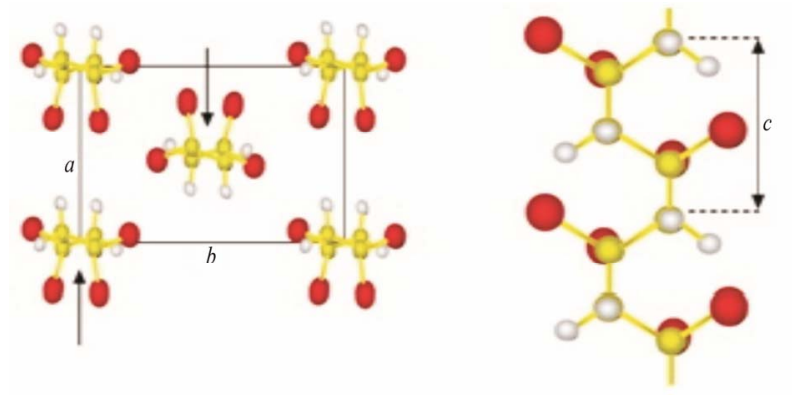

Figure 2. Chain structure of $\alpha$-phase in PVDF.
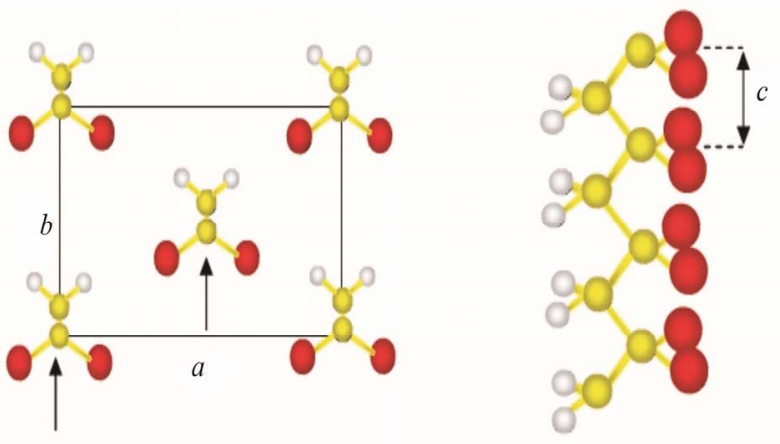

Figure 3. Chain structure of $\beta$-phase in PVDF.

tivity. Recently, PVDF with $\beta$-phase structure are widely developed due to molecules with this structure provides the greatest piezoelectric effect compared with other phase [4]. The $\alpha$ phase obtained by the crystallization of melt can be transformed to the $\beta$ phase by mechanical deformation [2]. Drawing at lower temperatures to the natural draw ratio of -4 and at higher temperatures to higher draw ratios $(>4)$ favors the transformation from $\alpha$ to $\beta$ phase [5-8]. From WAXD and FTIR studies, it is clear that there is $\alpha$ phase transformation during stretching and stretching at lower temperature to draw ratio of 4 or to higher draw ratios at higher temperature results in higher $\beta$ phase contents $[9,10]$.

The most common polymorph produced during crystallization from the melt is the $\alpha$-form; it is essentially the sole crystalline obtaoined at all temperatures up to $\approx 150^{\circ} \mathrm{C}$. Its crystallization kinetics have been studied by Gianotti et al. [11] in the range $147^{\circ} \mathrm{C}-165^{\circ} \mathrm{C}$, by Nakamura et al. [12], between $148^{\circ} \mathrm{C}-155^{\circ} \mathrm{C}$ and by Mancarella and Martuscelli [13] between $134^{\circ} \mathrm{C}$ and $149^{\circ} \mathrm{C}$. The dependence of crystalline and amorphous specific volume on temperature has been systematically studied by Nakagawa and Ishida [14].

Until now research on PVDF piezoelectric properties is still being developed, both in terms of increasing the piezoelectric material and the analysis of physical parameters related to the amount of beta fraction of the sample as well as in its application to sensors. In our research conducted by making a thin layer of material
PVDF polymer with Roll Hot Press for several different temperatures. Having obtained samples were then carried out characterization using XRD to analyze the influence of different temperatures on the manufacture of crystallite size of PVDF films [15].

Surface Resistivity value of PVDF film calculated by measurement using I-V meter. Electro active polymers, especially polyvinylidene fluoride, its polyvinylidene fluoride trifluoroethylene copolymer and cellular polymer ferroelectrics'-have interesting and useful piezoelectric and pyroelectric properties [16].

\section{Experiment}

In the experiments performed and characterization of PVDF film using such equipment; Roll Hot Press machine, micrometer screw, IV meter and X-Ray Diffraction. Initially, the PVDF samples in powder form were placed on the engine cylinder is then heated until it melts and then hot press roll device is operated to obtain a thin film. Fabrication of PVDF films made for variations in temperature from $130^{\circ} \mathrm{C}$ to $170^{\circ} \mathrm{C}$. PVDF film thickness was measured with a micrometer screw, the surface resistivity of film obtained by four point probes that was realized using $\mathrm{I}-\mathrm{V}$ meter, $\beta$ fraction and the crystalline phase is determined by using the X-Ray Diffraction. Roll hot press machine are shown in Figure 4.

The scheme of four point probes is shown in Figure 5.

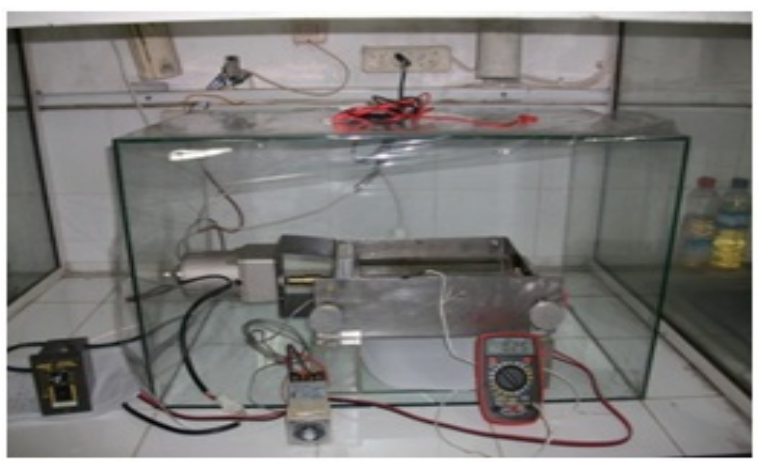

Figure 4. Roll hot press machine.

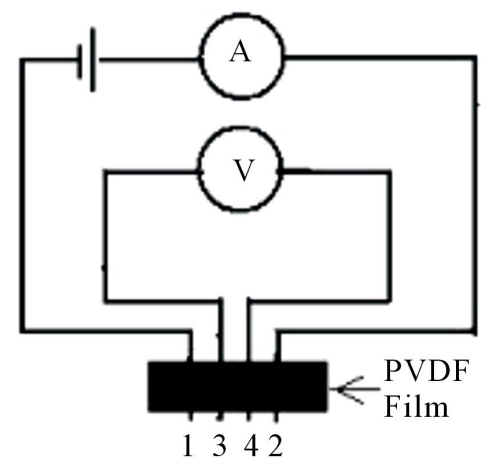

Figure 5. The point four probe scheme. 


\section{Results and Discussion}

PVDF films have been obtained with thicknesses of 13 $\mu \mathrm{m}$ as shown in Figure 6. Characterization results performed on samples by using XRD.

$\mathrm{X}$-Ray Diffraction characterization results of sample for temperature variation from $130^{\circ} \mathrm{C}$ to $170^{\circ} \mathrm{C}$ as shown in Figure 7.

XRD characterization results of sample with temperature at $130^{\circ} \mathrm{C}$ as shown in Figure 8.

While the results for the characterization of the sample for temperature at $135^{\circ} \mathrm{C}$ as shown in Figure 9.

Calculation to determine the amount of beta fraction of each sample using the Equation (1):

$$
F(\beta)=\frac{A_{\beta}}{1.26 A_{\alpha}+A_{\beta}} \times 100 \%
$$

From this characterization obtained $\beta$ fraction of sample for temperature variation $130^{\circ} \mathrm{C}$ to $170^{\circ} \mathrm{C}$ are shown in Table 1. Graph of increasing $\beta$ fraction with increas-

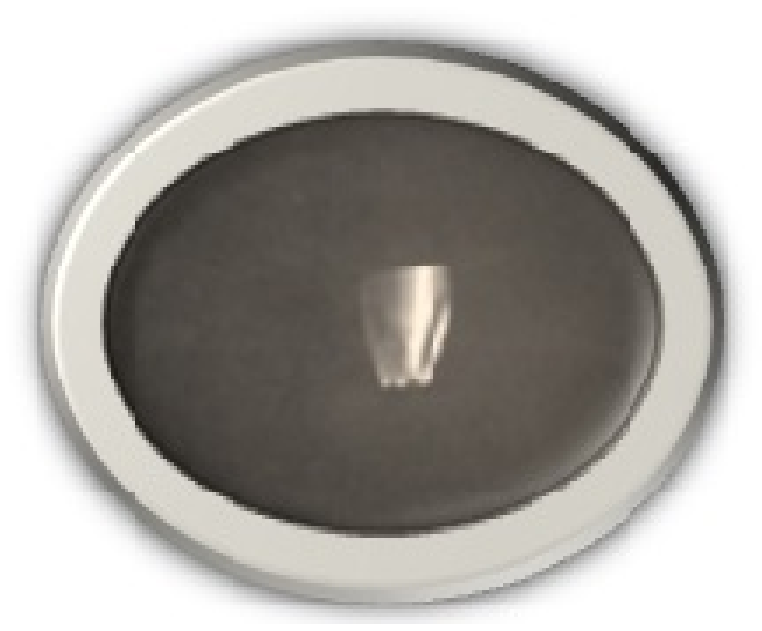

Figure 6. PVDF film produced.

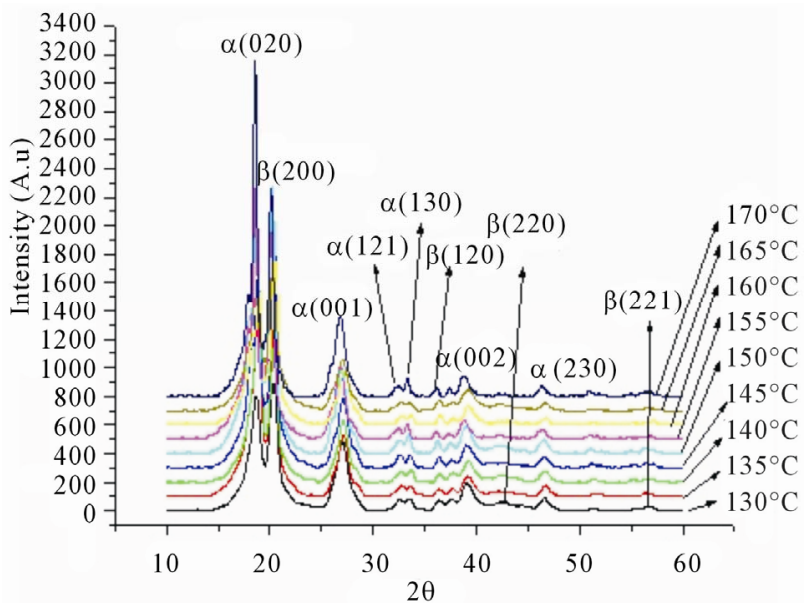

Figure 7. XRD results for sample at $130^{\circ} \mathrm{C}$ to $170^{\circ} \mathrm{C}$.

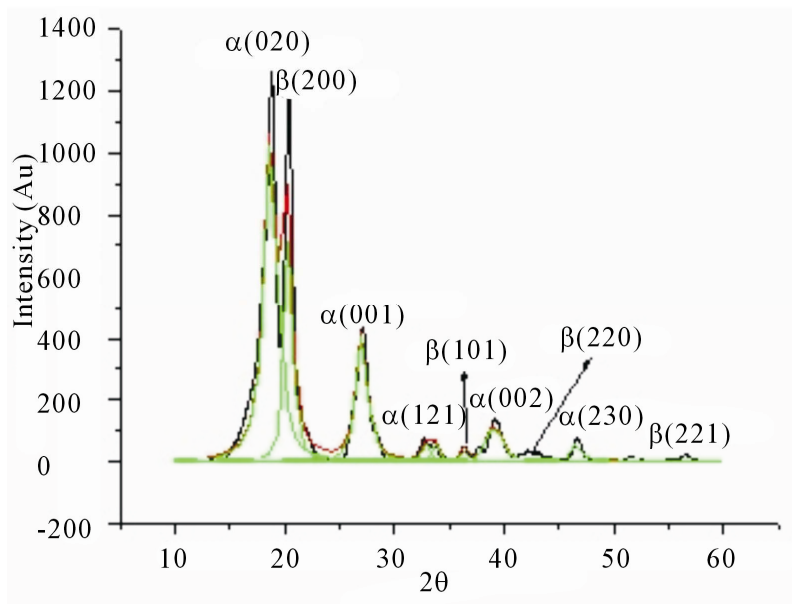

Figure 8. XRD results for sample at $130^{\circ} \mathrm{C}$.

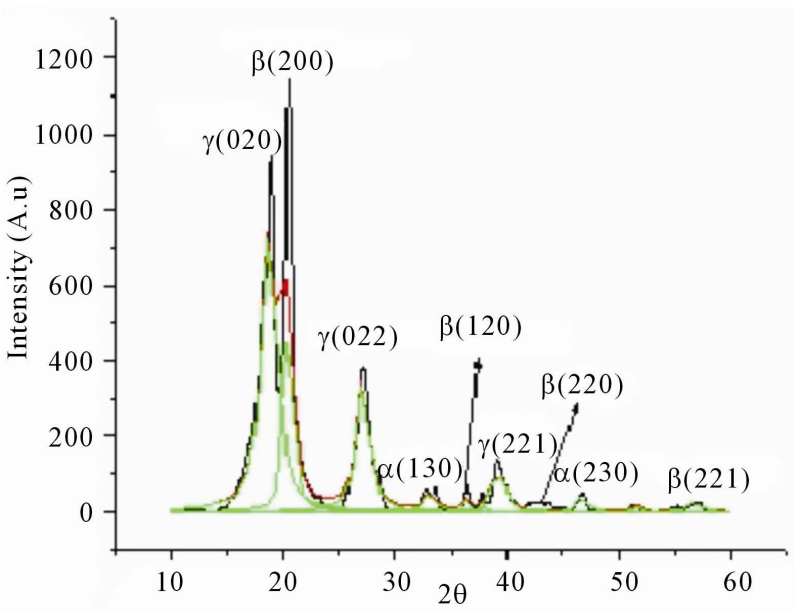

Figure 9. XRD results for sample at $135^{\circ} \mathrm{C}$.

ing temperature is shown in Figure 10.

The increase in temperature causes an increase in polarity due to the dipole orientation resulting in the transformation of the structure occurs. It is characterized by the addition of $\beta$ fraction [17].

The results of current-voltage measurements for the same thickness of $13 \mathrm{~nm}$ with a temperature variation of $130^{\circ} \mathrm{C}$ to $170^{\circ} \mathrm{C}$ are shown in Figure 11 .

The results of resistivity measurements show that the applied voltage is proportional to the increase in current, in accordance with Ohm's law.

$$
R=\frac{V}{I}
$$

where $R$ is resistance $(\Omega), V$ is applied voltage $(\mathrm{V})$ and $I$ is current $(\mathrm{A})$.

The value of $R$ can obtained from I-V curve gradient. Resistivity of sample calculated by Equation (3):

$$
\rho=2 \pi R S
$$


Table 1. $\beta$ fraction of sample for temperature variation from $130^{\circ} \mathrm{C}$ up to $170^{\circ} \mathrm{C}$.

\begin{tabular}{ccc}
\hline No & Temperature $\left({ }^{\circ} \mathrm{C}\right)$ & $\beta$ Fraction $(\%)$ \\
\hline 1 & 130 & 25.4 \\
2 & 135 & 26.34 \\
3 & 140 & 27.51 \\
4 & 145 & 29.23 \\
5 & 150 & 29.56 \\
6 & 155 & 35.5 \\
7 & 160 & 39.13 \\
8 & 165 & 41.07 \\
9 & 170 & 44 \\
\hline
\end{tabular}

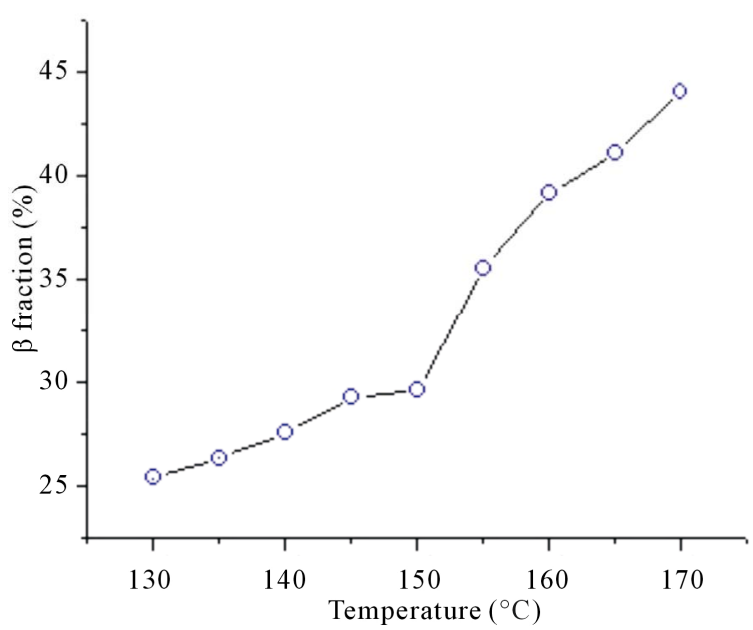

Figure 10. Graph of $\beta$ fraction increase to the temperature from $130^{\circ} \mathrm{C}$ to $170^{\circ} \mathrm{C}$.

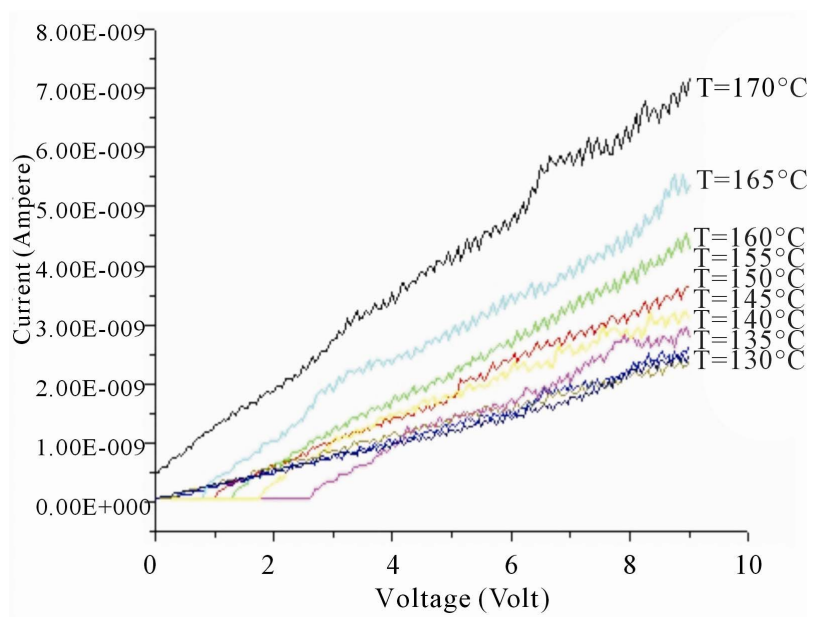

Figure 11. I-V curve of sample for variation temperature from $130^{\circ} \mathrm{C}$ to $170^{\circ} \mathrm{C}$. where $\rho$ is resistivity $(\Omega \mathrm{m})$ and $S$ is distance between the electrodes $(5 \mathrm{~mm})$. Surface Resistivity values of PVDF film for temperature $130^{\circ} \mathrm{C}$ to $170^{\circ} \mathrm{C}$ are decreased from $1.23 \times 10^{4} \Omega \mathrm{m}$ to $0.21 \times 10^{4} \Omega \mathrm{m}$ respectively. Graph of surface resistivity versus temperature are shown in Figure 12 .

While the temperature increase causes a decrease in the resistivity value, which indicates that there has been an increase in piezoelectric properties.

Crystallite size of PVDF film is determined by using Scherrer equation. Scherrer has derived an expression for broadening of x-ray diffraction peaks due only to small crystallite sizes [18]:

$$
B_{\text {crist }}=\frac{k \lambda}{L \cos \theta}
$$

where $\lambda$ is the wavelength of the x-ray used, $\theta$ is the Bragg angle, $L$ is the "average" crystallite size measured in a direction perpendicular to the surface of the specimen, and $k$ is a constant. Equation (4) is commonly known as the Scherrer equation and was derived based on uniform size. However, this equation is now frequently used to estimate the crystallite sizes of both cubic and noncubic materials. The constant $k$ has been determined to vary between 0.89 and 1.39 , but is usually taken as close to unity, the assumption that $k=1.0$ is generally justifiable.

In experiment for fabrication temperature is $130^{\circ} \mathrm{C}$, this pattern was indexed, and we found that these three reflections have indices (020), (200) and (001) at the $2 \theta$ value of $18.67,20.405$, and 27.09 , respectively. From this characterization and calculation has produces crystallite size is $7.2 \mathrm{~nm}$.

From second experiment for fabrication temperature is $135^{\circ} \mathrm{C}$, we found that these three reflections have indi-

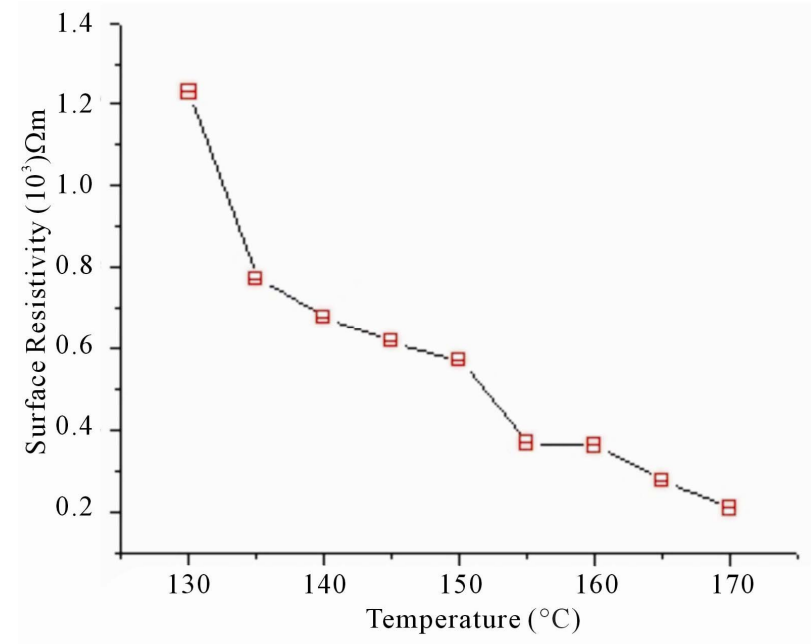

Figure 12. Graph resistivity as a function of temperature from $130^{\circ} \mathrm{C}$ to $170^{\circ} \mathrm{C}$. 
ces (020), (200) and (002) at the $2 \theta$ value of 18.72, 20.51, and 27.19, respectively. From this characterization and calculation has produces crystallite size is $7.9 \mathrm{~nm}$. From the difraction pattern for temperature $140^{\circ} \mathrm{C}$, we found that these three reflections have indices (020), (200) and (022) at the $2 \theta$ value of $18.63,20.40$, and 27.08 respectively. From this characterization and calculation has produces crystallite size is $19 \mathrm{~nm}$ [15].

Completely experimental results from this experiment are shown in Table 2.

These results show that increasing temperatures will

Table 2. Crystallite size for each sample.

\begin{tabular}{|c|c|c|c|c|}
\hline Temperature & $2 \theta$ & hkl & $\begin{array}{c}\mathrm{B}_{\mathrm{c}}(\mathrm{rad}) \operatorname{Cos} \theta \\
\quad\left(\times 10^{-2}\right)\end{array}$ & $\begin{array}{l}\text { Crystallite } \\
\text { size }(\mathrm{nm})\end{array}$ \\
\hline \multirow{3}{*}{$130^{\circ} \mathrm{C}$} & 18.67 & 020 & 2.27 & \multirow{3}{*}{7.2} \\
\hline & 20.405 & 200 & 1.76 & \\
\hline & 27.09 & 001 & 2.42 & \\
\hline \multirow{3}{*}{$135^{\circ} \mathrm{C}$} & 18.72 & 020 & 2.25 & \multirow{3}{*}{7.9} \\
\hline & 20.51 & 200 & 2.09 & \\
\hline & 27.19 & 002 & 1.5 & \\
\hline \multirow{3}{*}{$140^{\circ} \mathrm{C}$} & 18.63 & 020 & 2.41 & \multirow{3}{*}{8.7} \\
\hline & 20.40 & 200 & 1.61 & \\
\hline & 27.08 & 022 & 1.57 & \\
\hline \multirow{3}{*}{$145^{\circ} \mathrm{C}$} & 18.72 & 020 & 2.032 & \multirow{3}{*}{10.93} \\
\hline & 20.51 & 200 & 1.093 & \\
\hline & 27.18 & 022 & 1.102 & \\
\hline \multirow{3}{*}{$150^{\circ} \mathrm{C}$} & 18.49 & 020 & 0.84 & \multirow{3}{*}{14} \\
\hline & 20.225 & 200 & 1.241 & \\
\hline & 26.92 & 022 & 1.181 & \\
\hline \multirow{3}{*}{$155^{\circ} \mathrm{C}$} & 18.57 & 020 & 1.436 & \multirow{3}{*}{14.67} \\
\hline & 20.37 & 200 & 0.809 & \\
\hline & 27.00 & 022 & 0.901 & \\
\hline \multirow{3}{*}{$160^{\circ} \mathrm{C}$} & 18.50 & 020 & 0.510 & \multirow{3}{*}{19} \\
\hline & 20.31 & 200 & 0.335 & \\
\hline & 26.99 & 022 & 1.677 & \\
\hline \multirow{3}{*}{$165^{\circ} \mathrm{C}$} & 18.80 & 020 & 0.414 & \multirow{3}{*}{19.7} \\
\hline & 20.44 & 200 & 0.99 & \\
\hline & 27.08 & 022 & 1.065 & \\
\hline \multirow{3}{*}{$170^{\circ} \mathrm{C}$} & 17.75 & 110 & 0.276 & \multirow{3}{*}{20.54} \\
\hline & 18.56 & 020 & 1.253 & \\
\hline & 20.12 & 200 & 0.731 & \\
\hline
\end{tabular}

also increase the size of the crystallite of the sample. This happens because with the increasing temperature causes the higher the degree of crystallization of PVDF film sample is formed, so that the crystallite size also increases.

\section{Conclusion}

Has been successfully produced PVDF films with using roll hot press. XRD characterization showed increase in the $\beta$ fraction when the temperature is raised. PVDF films showed a decrease in resistivity for every increase of temperature. This indicates that mechanical treatment to produce film thickness and temperature has a strong influence on the $\beta$ fraction of PVDF films. Increasing of temperatures will also increase the size of the crystallite of the sample. This happens because with the increasing temperature causes the higher the degree of crystallization of PVDF film sample is formed, so that the crystallite size also increases.

\section{Acknowledgements}

The authors thank to Mr. Priambodo as laborant at Integrated Centre Laboratory of State Islamic University (UIN JAKARTA) for support in X-Ray Diffraction Characterization.

\section{REFERENCES}

[1] C. L. Radiman, "Kimia Polimer," Penerbit ITB, Bandung, 2004, pp. 5-20.

[2] A. J. Lovinger, "Poly(Vinylidene fluoride)," In: D. C. Bassett, Ed., Development in Crystalline Polymers, Applied Science Publisher, London, 1982, pp. 195-261.

[3] A. J. Lovinger, "Poyivinylidene Fluoride," Applied Science Publisher, London, 1981, p. 202.

[4] A. Hartono, S. Satira, M. Djamal, Ramli and E. Sanjaya, "Effect of Mechanical Treatment Temperature and Layer Thickness on Piezoelctic Properties PVDF Film," Proceedings of APS, 2012.

[5] K. Matsushige, K. Nagata, S. Imada and T. Takemura, "The II-I Crystal Transformation of Poly(vinylidene fluoride) under Tensile and Compressional Stresses," Polymer, Vol. 21, No. 12, 1980, pp. 1391-1397. doi:10.1016/0032-3861(80)90138-X

[6] J. C. Mcgrath, "High Effective Draw as a Route to Increased Stiffness and Electrical Response in Poly(vinylidene fluoride)," Polymer, Vol. 21, No. 8, 1980, pp. 855-857. doi:10.1016/0032-3861(80)90237-2

[7] J. Humphreys, et al., "A Study of the Drawing Behavior of Polyvinylidene Fluoride," Journal of Applied Polymer Science, Vol. 30, No. 10, 1985, pp. 4069-4079. doi:10.1002/app.1985.070301010

[8] T. Hsu and P. J. Geil, "Deformation and Transformation Mechanisms of Poly(vinylidene fluoride) $\left(\mathrm{PVF}_{2}\right)$," Journal of Materials Science, Vol. 24, No. 4, 1989, pp. 1219- 
1232. doi:10.1007/BF02397050

[9] V. Sencadas, V. M. Moreira, S. Lanceros-Mendez, A. S. Pouzada and R. Gregorio Jr., " $\alpha$ - to- $\beta$ Transformation on PVDF Films Obtained by Uniaxial Stretch," Materials Science Forum, Vol. 514-516, 2006, pp. 872-876. doi:10.4028/www.scientific.net/MSF.514-516.872

[10] R. P. Vijayakumar, D. V. Khakhar and A. Misra, "Studies on A to B Phase Transformations in Mechanically Deformed PVDF Films," Journal of Applied Polymer Science, Vol. 117, 2010, pp. 3491-3497.

[11] G. Gianotti, A. Capizzi and V. Zamboni, Chim. e Industr., Vol. 55, 1973, 1973, p. 501.

[12] S. Nakamura, T. Sasaki, J. Funamoto and K. Matsuzaki, "Dynamic Cooling and Isothermal Crystallizations of Poly (vinylidene fluoride) from the Melt," Die Makromolekulare Chemie, Vol. 176, No. 11, 1975, pp. 3471-3481. doi:10.1002/macp.1975.021761128

[13] C. Mancarella and E. Martuscelli, "Crystallization Kinetics of Poly(vinylidene fluoride)," Polymer, Vol. 18, No. 12, 1977, pp. 1240-1242. doi:10.1016/0032-3861(77)90286-5

[14] K. Nakagawa and Y. Ishida, "Estimation of Amorphous Specific Volume of Poly(vinylidene fluoride) as a Function of Temperature," Kolloid-Zeitschrift und Zeitschrift für Polymere, Vol. 251, No. 2, 1973, pp. 103-107. doi:10.1007/BF01498933

[15] A. Hartono, S. Satira, M. Djamal, R. Ramli, H. Bahar and E. Sanjaya, "Effect of Fabrication Temperature on Crystallite Size of PVDF Film," Proceedings of ICMNS, 2012.

[16] S. B. Lang and S. Muensit, "Review of Some LesserKnown Applications of Piezoelectric and Pyroelectric Polymers," Applied Physics A, Vol. 85, No. 2, 2006, pp. 125 134. doi:10.1007/s00339-006-3688-8

[17] A. Hartono, R. Ramli and M. D. dan S. Satira, "Pengaruh Temperatur Perlakuan Mekanik Terhadap Jumlah Fraksi $\beta$ dan Resistivitas Permukaan Lapisan PVDF," BKS PTN$B M I P A-2012$, Universitas Negeri Medan, Medan, 2012, pp. 17-22.

[18] C. Suryanarayana and M. G. Norton, "X-Ray Diffraction a Practical Approach,” Plenum Press, New York, 1998. 